\title{
Exercise Testing, Family History, and Subclinical Atherosclerosis Markers for Cardiovascular Risk Reclassification in Middle-Aged Women
}

Ricardo Quental Coutinho, ${ }^{10}$ Ulisses Ramos Montarroyos, ${ }^{1 \oplus}$ Isly Maria Lucena de Barros, ${ }^{1 \oplus}$ Maria José Bezerra Guimarães, ${ }^{1 \odot}$ Ana Paula Dornelas Leão, ${ }^{\circledR}$ Laura Olinda Bregieiro Fernandes Costa, ${ }^{1 \oplus}$ Ana Kelley de Lima Medeiros, ${ }^{\circledR}$ Maria de Fátima Monteiro, ${ }^{1 \oplus}$ Moacir de Novaes Lima Ferreira, ${ }^{1 \oplus}$ William Azem Chalela, ${ }^{\circledR}$ Rodrigo $^{\circ}$ Pinto Pedrosa ${ }^{1}$

Universidade de Pernambuco, ${ }^{1}$ Recife, $P E-$ Brazil

Universidade de São Paulo, 2 São Paulo, SP - Brazil

\section{Abstract}

Background: Cardiovascular diseases are the main cause of death in women and the accuracy of currently available risk scores is questionable.

Objective: To reclassify the risk estimated by the Framingham Risk Score (FRS) in asymptomatic middle-aged women by incorporating family history, exercise testing variables, and subclinical atherosclerosis markers.

Methods: This cross-sectional study included 509 women (age range, 46-65 years) without cardiovascular symptoms. Those at low or intermediate risk by the FRS were reclassified to a higher level considering premature family history of acute myocardial infarction and/or sudden death; four variables from exercise testing; and two variables related to subclinical atherosclerosis markers. The homogeneity of these variables according to the FRS was verified by Pearson chi-square test $(\mathrm{p}<0.05)$.

Results: According to the FRS, $80.2 \%, 6.2 \%$, and $13.6 \%$ of the women were classified as low $(<5 \%)$, intermediate $(5-10 \%)$, and high $(>10 \%)$ risks, respectively. The intermediate-risk stratum showed the highest increase (from $6.2 \%$ to $33.3 \%$ ) with addition of family history; followed by addition of chronotropic index $<80 \%$ (to $24.2 \%$ ); functional capacity $<85 \%(22.2 \%)$, coronary calcium score $>0(20.6 \%)$; decreased one-minute heart rate recovery $\leq 12 \mathrm{bpm}$ $(15.2 \%)$; carotid intima-media thickness $>1 \mathrm{~mm}$ and/or carotid plaque (13.8\%) and ST-segment depression (9.0\%). The high-risk stratum increased to $14.4 \%$ with the addition of reduced heart rate recovery and to $17.1 \%$ with the coronary calcium score.

Conclusion: Incorporation of premature family history of cardiovascular events, exercise testing abnormal parameters, and subclinical atherosclerosis markers into the FRS led to risk reclassification in $3.0-29.7 \%$ of asymptomatic middle-aged women, mainly by an increase from low to intermediate risk.

Keywords: Exercise Test; Heredity; Atherosclerosis; Women; Middle Aged; Estrogens; Risk Factor; Obesity; Hypertension; Myocardial Infarction; Sudden death.

\section{Introduction}

In middle-aged women, estrogen deficiency and the high prevalence of traditional risk factors such as obesity, sedentary behavior and hypertension can cause significant changes in the cardiovascular risk profile. ${ }^{1,2}$ Although approximately $90 \%$ of these women are classified

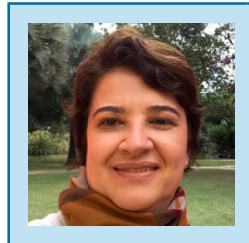
Isly Lucena, MD, PhD Medical assistant of the Clinic Coronary Unit - Cardiac Emergency Hospital of Pernambuco (PROCAPE-UPE) 
as "low risk" based on the Framingham Risk Score (FRS), events such as acute myocardial infarction and sudden death are common in this group, ${ }^{3,4}$ suggesting that traditional cardiovascular risk scores may not be accurate. ${ }^{3,5-7}$ Thus, variables not included in the traditional scores, such as a premature family history of cardiovascular events, ${ }^{3,4}$ exercise testing variables, ${ }^{4,5-10}$ and subclinical atherosclerosis markers have been considered for risk reclassification in women. ${ }^{8,9,11,12}$ In addition, a history of infarction or death from cardiovascular disease in first-degree male relatives before 55 years of age and female relatives before 60 years of age has been considered in this regard. ${ }^{1,10,13}$ The prevalence of subclinical atherosclerosis is found to be high in women with a family history of cardiovascular events, even in those at low risk according to the FRS. ${ }^{12,13}$

Among the markers of subclinical atherosclerosis, coronary calcium score has been of increasing interest, especially in asymptomatic individuals deemed to be at intermediate risk by the FRS, ${ }^{3,14,15}$ since it is able to detect coronary calcifications that correlate with disease extent and cardiovascular events. ${ }^{16,17}$ Another marker of subclinical atherosclerosis, carotid intima-media thickness (CIMT), assessed by ultrasonography, is associated with the presence and extent of disease in both men and women, and a predictor of myocardial infarction and stroke. ${ }^{11,18,19}$

Exercise testing, a non-invasive functional method established in the field of cardiology, is not only of high diagnostic value, but also of prognostic value, including in asymptomatic women. ${ }^{20-23}$ In this sense, valuable information can be obtained regarding the prediction of cardiovascular risk when exercise parameters - functional capacity, chronotropic response, chronotropic index, heart rate (HR) recovery, and ventricular ectopy after exercise - are assessed..$^{24-30}$

Studies have demonstrated the prognostic role of imaging and functional tests, alone but especially in combination, to identify which women are at greatest risk for cardiovascular events. ${ }^{31-33}$ Thus, markers of subclinical atherosclerosis and exercise testing variables may contribute to the adoption of earlier and more effective preventive measures, ${ }^{8,9,18,33,34}$ especially in those initially classified as low or intermediate risk by the FRS.

In this context, the purpose of this study was to reclassify the risk estimated by the FRS in asymptomatic middleaged women with the incorporation of a premature family history of cardiovascular events, exercise testing variables, and subclinical atherosclerosis markers.

\section{Materials and methods}

\section{Study design and participants}

It was a cross-sectional study with women aged 46-65 years selected by convenience sampling at two women's health outpatient clinics. The sample studied $(n=509)$ was greater than the calculated sample size $(n=384)$, obtained by the method recommended when the frequency of the event in an infinite population is unknown. ${ }^{35}$ For sample calculation, we used: estimated frequency in the population (proportion of women whose cardiovascular risk was assessed by the two methods) equal to $50 \%$, using the maximum possible variability; $95 \%$ confidence interval; $5 \%$ margin of error; and infinite population size. The following exclusion criteria were adopted: history or clinical evidence of cardiovascular disease, except hypertension; diagnosis of liver or kidney disease; use of corticosteroids or hormone replacement therapy; pregnancy; use of intrauterine device; use of hormonal contraceptives for at least one year; and contraindication to exercise testing according to the III Brazilian Society of Cardiology Guideline for Exercise Testing. ${ }^{20}$

\section{Variables and data collection}

Of all women participating in the study, the following data were collected - age, weight, height, smoking habit, history of diabetes and systemic arterial hypertension, use of HR-reducing medication, and history of parents and siblings ( $<60$ years of age for female relatives and $<55$ years of age for male relatives) with acute myocardial infarction and/or sudden death. Measurement of blood pressure, serological tests (fasting glycemia, total cholesterol and fractions, triglycerides), exercise testing, carotid artery ultrasound (for determination of CIMT), and chest tomography (to determine the coronary calcium score) were performed.

The FRS was obtained from variables including age, total cholesterol and fractions, blood pressure, and smoking. The FRS was categorized into three strata of cardiovascular risk, low $(<5 \%)$, intermediate (5-10\%), and high ( $>10 \%)$, according to the American Heart Association ${ }^{5}$ and the Brazilian Society of Cardiology ${ }^{9}$ recommendations for female patients. All diabetic women were classified as "high risk".

Exercise testing was performed by the principal investigator following the symptom-limited Bruce protocol $^{36}$ (Inbramed $\AA$ treadmill, using the ErgoPc $₫$ exercise testing program and a Unitec ${ }^{\circledR}$ mercury manometer). Interpretation of the exercise testing results 
was made according to the parameters established by the Brazilian Society of Cardiology. ${ }^{20}$ For calculation of the exercise testing variables considered predictors of mortality, the following formulae were used:21,23 (a) Functional capacity $=\left(\right.$ maximum $\mathrm{VO}_{2}$ reached $\left.\times 100\right) / \mathrm{VO}_{2}$ predicted considering the predicted $\mathrm{VO}_{2}=14.7-(0.13 \times$ age); (b) chronotropic index $=$ (maximum HR - resting $H R) \times 100 /($ predicted HR - resting HR). The predicted HR was considered as (220 - age) as recommended by Karnoven et al. ${ }^{37}$ and (c) decrease in HR recovery at 1 minute $=$ maximum $\mathrm{HR}-\mathrm{HR}$ recovery at 1 minute.

CIMT was measured by carotid artery ultrasound (123-MHz EnVisor Ultrasound System; Philips Ultrasound, Bothell, WA, USA) by the same technician. The average of maximum CIMT was obtained from the right and left carotid segments. CIMT values $>1 \mathrm{~mm}$ and the presence of atheroma plaque in the carotid artery ${ }^{18}$ were used as indicators of subclinical carotid atherosclerosis. Carotid plaque was defined as the presence of focal wall thickening at least $50 \%$ greater than the wall thickness of the surrounding vessel or as a focal region with an intima-media thickness $>1.5 \mathrm{~mm}$ projecting to the lumen distinct from the adjacent contour. ${ }^{18}$

For coronary calcium score, non-contrast chest tomography with low effective radiation dose (1.7$2.5 \mathrm{mSv}$ ) was performed by multi-channel detector computed tomography (Philips Brilliance CT-10; Philips, Amsterdam, The Netherlands). Images were prospectively obtained using the single 20 -second acquisitions of deepinspiration breath-hold technique and synchronized with electrocardiogram to obtain 3-mm cuts from the level of the carina to the level of the diaphragm. ${ }^{12,15}$ Coronary calcification was defined as a plaque of at least three consecutive pixels (area $=1.03 \mathrm{~mm}^{2}$ ) with density $\geq 130$ Hounsfield units (HU). The coronary calcium score was calculated according to the method described by Agatston, ${ }^{38}$ i.e., multiplying the area of calcification in square millimeters by a factor of $1,2,3$, or 4 depending on attenuation coefficients determined by calcium. Factor 1 was used when the coefficients were 130-199 HU; factor 2, 200-299 HU; factor 3, 300-399 HU; and factor 4, >400 HU.

\section{Statistical analysis}

Continuous variables are presented as mean and standard deviation, and categorical variables as absolute and relative frequencies. Homogeneity of the variables used for cardiovascular risk reclassification was verified by the Pearson chi-square test $(p<0.05)$.
Women classified as "low" or "intermediate" cardiovascular risk based on the FRS were reclassified to "high" risk if they had one or more of the following parameters: (a) premature family history of acute myocardial infarction and/or sudden death; (b) chronotropic index $<80 \%$ or $<62 \%$ if using HR-lowering medication; (c) functional capacity $<85 \%$; (d) decrease in HR recovery at 1 minute $\leq 12$ bpm; (e)ST-segment depression; (f) CIMT >1 mm and/or presence of carotid plaque; or (g) coronary calcium score $>0$.

With the incorporation of premature family history of cardiovascular events, exercise test variables, and atherosclerosis markers into the FRS, the increase in cardiovascular risk corresponded to the proportion of participants who were reclassified to a higher risk level. The database was built in the Microsoft Office Access program and analysis was performed using the SPSS program (version 21.0).

\section{Results}

More than one-third of the middle-aged women participating in the study (mean age, $56.4 \pm 4.8$ years; body mass index, $27.8 \pm 4.9 \mathrm{~kg} / \mathrm{m}^{2}$ ) had systemic arterial hypertension, dyslipidemia, and obesity (Table 1). Among them, $11.2 \%$ were diabetic and $7.7 \%$ reported smoking. Approximately $11.0 \%$ were using HR-reducing medication to control systemic arterial hypertension. In the exercise testing (Table 1), mean values of maximal $\mathrm{HR}$, exercise time, and $\mathrm{VO}_{2}$ were adequate for test interpretation.

Among the variables incorporated into the FRS for cardiovascular risk reclassification (Table 2), premature family history of acute myocardial infarction and/or sudden death was the most frequent (more than one-third of participants), followed by chronotropic index, with almost one-third of participants with values below $80 \%$ or $62 \%$ (in users of HR-lowering drugs). The lowest frequency was related to ST-segment depression, observed in 22 women (4.4\%), of whom only 11 (2.2\% of the total sample) had a horizontal or descending pattern $(>1 \mathrm{~mm})$, suggestive of myocardial ischemia. According to the FRS strata, differences $(p<0.05)$ were observed only in the distribution of the chronotropic index and carotid calcium score.

As shown in Figure 1, about $6 \%$ of the women were classified as intermediate risk by the FRS. After the variables of interest were added, the percentage of women at this stratum increased, with the highest increment (to 33.3\%) after the addition of premature family history of cardiovascular events, followed by low chronotropic index (24.2\%) and impairment in functional capacity $(22.2 \%)$ (Figure 1 ). 
Table 1 - Characteristics of participants and exercise testing parameters

\begin{tabular}{|c|c|}
\hline Variable & $\begin{array}{c}\text { Value } \\
(n=509)\end{array}$ \\
\hline \multicolumn{2}{|l|}{ Age group $[n(\%)]$, years } \\
\hline $46-55$ & $231(46.1 \%)$ \\
\hline $56-60$ & $147(29.3 \%)$ \\
\hline $61-65$ & $123(24.6 \%)$ \\
\hline Age $($ mean $\pm S D)$, years & $56.4 \pm 4.8$ \\
\hline $\mathrm{BMI}($ mean $\pm \mathrm{SD}), \mathrm{kg} / \mathrm{m}^{2}$ & $27.8 \pm 4.9$ \\
\hline Obesity [n (\%)] & $158(31.1 \%)$ \\
\hline Diabetes [n (\%)] & $57(11.2 \%)$ \\
\hline Systemic arterial hypertension [n (\%)] & $247(48.5 \%)$ \\
\hline Dyslipidemia [n (\%)] & $211(41.5 \%)$ \\
\hline Smoking [n (\%)] & $39(7.7 \%)$ \\
\hline Coronary calcium score (mean \pm SD) & $21.4 \pm 89.7$ \\
\hline CIMT $($ mean \pm SD)], mm & $0.6 \pm 0.1$ \\
\hline HR-lowering medication [n (\%)] & $57(11.2 \%)$ \\
\hline \multicolumn{2}{|l|}{ Exercise testing } \\
\hline HR response (mean $\pm \mathrm{SD}), \mathrm{bpm}$ & $74.4 \pm 13.3$ \\
\hline Maximum HR (mean \pm SD), bpm & $152.5 \pm 19.6$ \\
\hline $\mathrm{HR}$ recovery at 1 minute (mean $\pm \mathrm{SD}$ ), bpm & $130.7 \pm 19.3$ \\
\hline Chronotropic index (mean \pm SD), \% & $88.4 \pm 20.8$ \\
\hline Decreased HR recovery at 1 minute (mean $\pm \mathrm{SD}$ ), bpm & $21.8 \pm 9.1$ \\
\hline Functional capacity (mean \pm SD), $\%$ & $104.1 \pm 26.9$ \\
\hline Exercise time, (mean $\pm \mathrm{SD})$, minutes & $7.4 \pm 2.1$ \\
\hline $\mathrm{VO}_{2}($ mean $\pm \mathrm{SD}), \mathrm{METs}$ & $7.6 \pm 2.0$ \\
\hline Arrhythmia [n (\%)] & $43(9.9 \%)$ \\
\hline
\end{tabular}

Regarding the percentage of women at high risk based on the FRS (13.6\% of the women), after reclassification, it increased to $14.4 \%$ with the addition of one-minute HR recovery $\leq 12 \mathrm{bpm}$ and to $17.1 \%$ with the addition of a calcium score $>0$. The percentage of women at low risk based on the FRS $(80.2 \%)$ decreased due to the migration of women to the strata of higher risk, from $80.2 \%$ to $50.6 \%$ when considering a premature family history of a cardiovascular event, and to $77.2 \%$ when considering the ST-segment depression.

With the incorporation of the variables used to reclassify cardiovascular risk of asymptomatic middle-aged women
(Figure 2), the total increase in risk (low to intermediate and intermediate to high) ranged from 3.0\% (ST-segment depression) to $29.7 \%$ (premature family history of cardiovascular event). For all variables considered, the highest increment occurred in the intermediate-risk stratum.

\section{Discussion}

This study demonstrated that adding the variables premature family history of cardiovascular events, exercise test parameters, and markers of subclinical 
Table 2 - Prevalence of premature family history of cardiovascular events, exercise testing variables, and subclinical atherosclerosis markers in asymptomatic middle-aged women according to the Framingham Risk Score classification

\begin{tabular}{|c|c|c|c|c|c|c|c|c|c|}
\hline \multirow{3}{*}{ Variable } & \multicolumn{8}{|c|}{ Framingham Risk Score } & \multirow{3}{*}{$\mathrm{p}^{+}$} \\
\hline & \multicolumn{2}{|c|}{ Low } & \multicolumn{2}{|c|}{ Intermediate } & \multicolumn{2}{|c|}{ High } & \multicolumn{2}{|c|}{ Total } & \\
\hline & $\mathbf{N}$ & $\%$ & $\mathbf{N}$ & $\%$ & $\mathbf{N}$ & $\%$ & $\mathbf{N}$ & $\%$ & \\
\hline \multicolumn{10}{|c|}{ Premature family history of AMI and/or sudden death } \\
\hline Yes & 146 & 37.0 & 13 & 41.9 & 25 & 37.9 & 184 & 37.4 & 0.856 \\
\hline Not & 249 & 63.0 & 18 & 58.1 & 41 & 62.1 & 308 & 62.6 & \\
\hline \multicolumn{10}{|l|}{ Chronotropic index } \\
\hline Altered $\left(<62 \%{ }^{\ddagger} /<80 \%\right)$ & 104 & 25.9 & 14 & 45.2 & 22 & 32.4 & 140 & 28.0 & 0.049 \\
\hline Normal & 297 & 74.1 & 17 & 54.8 & 46 & 67.6 & 360 & 72.0 & \\
\hline \multicolumn{10}{|l|}{ Decreased HR recovery at 1 minute } \\
\hline Altered ( $\leq 12$ bpm) & 52 & 12.9 & 5 & 16.7 & 12 & 17.6 & 69 & 13.8 & 0.520 \\
\hline Normal & 350 & 87.1 & 25 & 83.3 & 56 & 82.4 & 431 & 86.2 & \\
\hline \multicolumn{10}{|l|}{ Functional capacity } \\
\hline Altered $(<85 \%)$ & 90 & 22.4 & 8 & 25.8 & 20 & 29.4 & 118 & 23.6 & 0.430 \\
\hline Normal & 312 & 77.6 & 23 & 74.2 & 48 & 70.6 & 383 & 76.4 & \\
\hline \multicolumn{10}{|l|}{ ST-segment depression } \\
\hline Yes & 15 & 3.7 & 1 & 3.2 & 6 & 8.8 & 22 & 4.4 & 0.157 \\
\hline Not & 387 & 96.3 & 30 & 96.8 & 62 & 91.2 & 479 & 95.6 & \\
\hline \multicolumn{10}{|l|}{ Coronary calcium score } \\
\hline Zero & 264 & 76.5 & 13 & 52.0 & 41 & 71.9 & 318 & 74.5 & 0.022 \\
\hline $1-99$ & 68 & 19.7 & 8 & 32.0 & 9 & 15.8 & 85 & 19.9 & \\
\hline$\geq 100$ & 13 & 3.8 & 4 & 16.0 & 7 & 12.3 & 24 & 5.6 & \\
\hline \multicolumn{10}{|l|}{ CIMT } \\
\hline$\leq 1 \mathrm{~mm}$ & 360 & 89.6 & 27 & 87.1 & 55 & 80.9 & 442 & 88.2 & 0.120 \\
\hline$>1 \mathrm{~mm}$ and/or carotid plaque & 42 & 10.4 & 4 & 12.9 & 13 & 19.1 & 59 & 11.8 & \\
\hline \multicolumn{10}{|c|}{$\begin{array}{l}\text { AMI: acute myocardial infarction; HR: heart rate; CIMT: carotid intima-media thickness. } \\
{ }^{*} \text { Framingham Risk Score: low }(<5 \%) \text {, intermediate }(5-10 \%), \text { high }(>10 \%) ;{ }^{+} \text {-value referring to the Pearson chi-square test; }{ }^{*} \text { Chronotropic index } \\
<62 \% \text { only in women using heart rate-lowering medication. } \\
\text { Note: Women with incomplete information were excluded from the analyses. }\end{array}$} \\
\hline
\end{tabular}

atherosclerosis to the FRS provided a cardiovascular risk reclassification in asymptomatic, middle-aged women. Among the seven variables used, ST-segment depression contributed to the smallest increase (3\%) in cardiovascular risk when added to the FRS, while other variables like premature family history of cardiovascular events (about 30\%) and altered chronotropic index (about $21 \%$ ) contributed to the largest increases.
Despite the recognized importance of the FRS, studies $^{3,27,29}$ have drawn attention to the use of some variables for reclassification of the cardiovascular risk in middle-aged women, since although most of them are classified as low risk by the FRS, some are affected by acute myocardial infarction, even without previous symptoms. Thus, for women at low or intermediate risk based on the FRS, with one or more risk factors or 


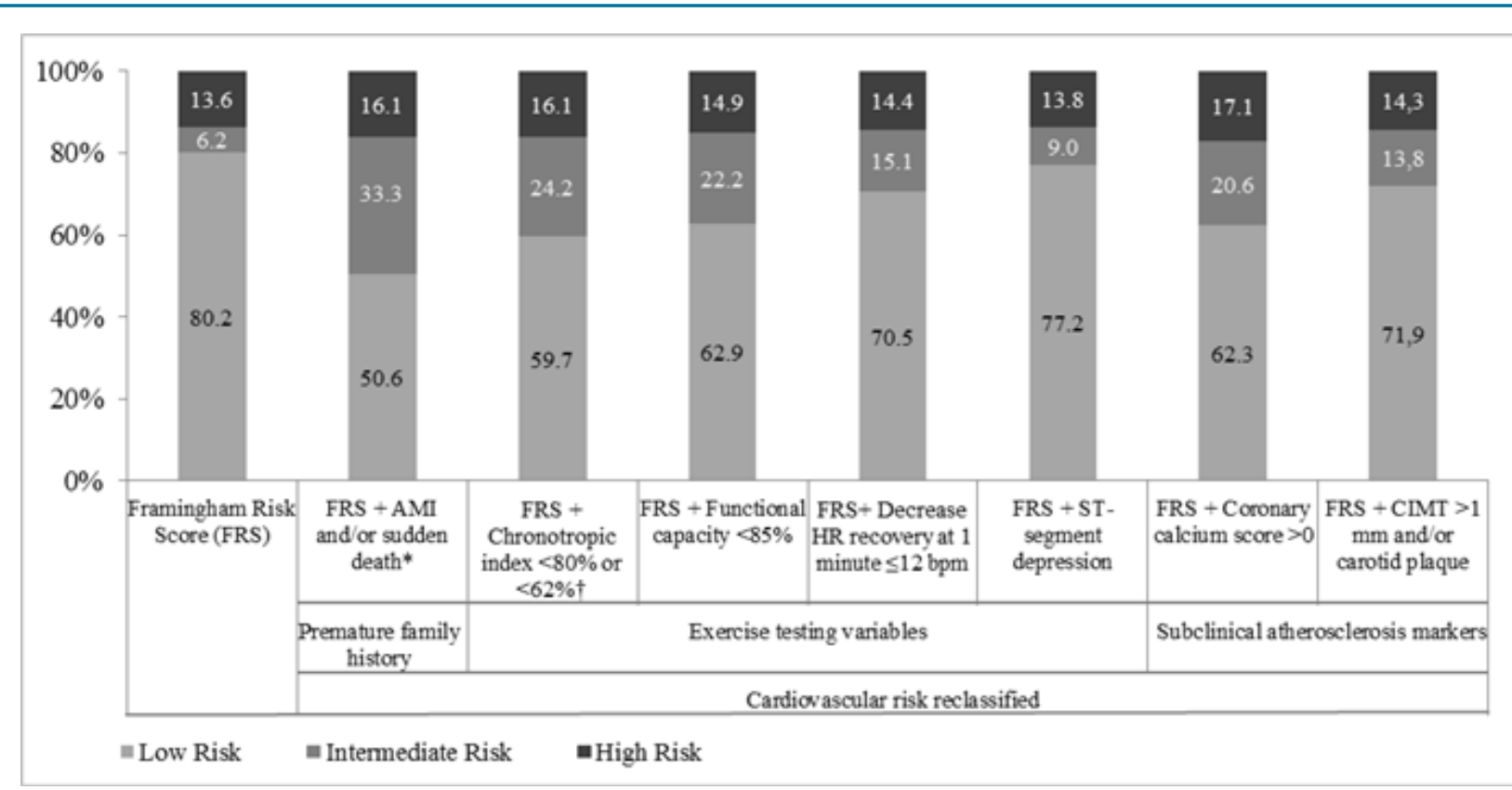

Figure 1 - Proportion of asymptomatic middle-aged women by Framingham Risk Score strata and by risk reclassification after addition of premature family history of cardiovascular event, exercise testing variables, and subclinical atherosclerosis markers FRS: Framingham Risk Score; AMI: acute myocardial infarction; HR: heart rate; CIMT: carotid intima-media thickness.

*History of acute myocardial infarction (AMI) and/or sudden death in parents and/or siblings younger than 55 years (men) or 60 years (women); tChronotropic index $<62 \%$ if using heart rate-lowering medication.

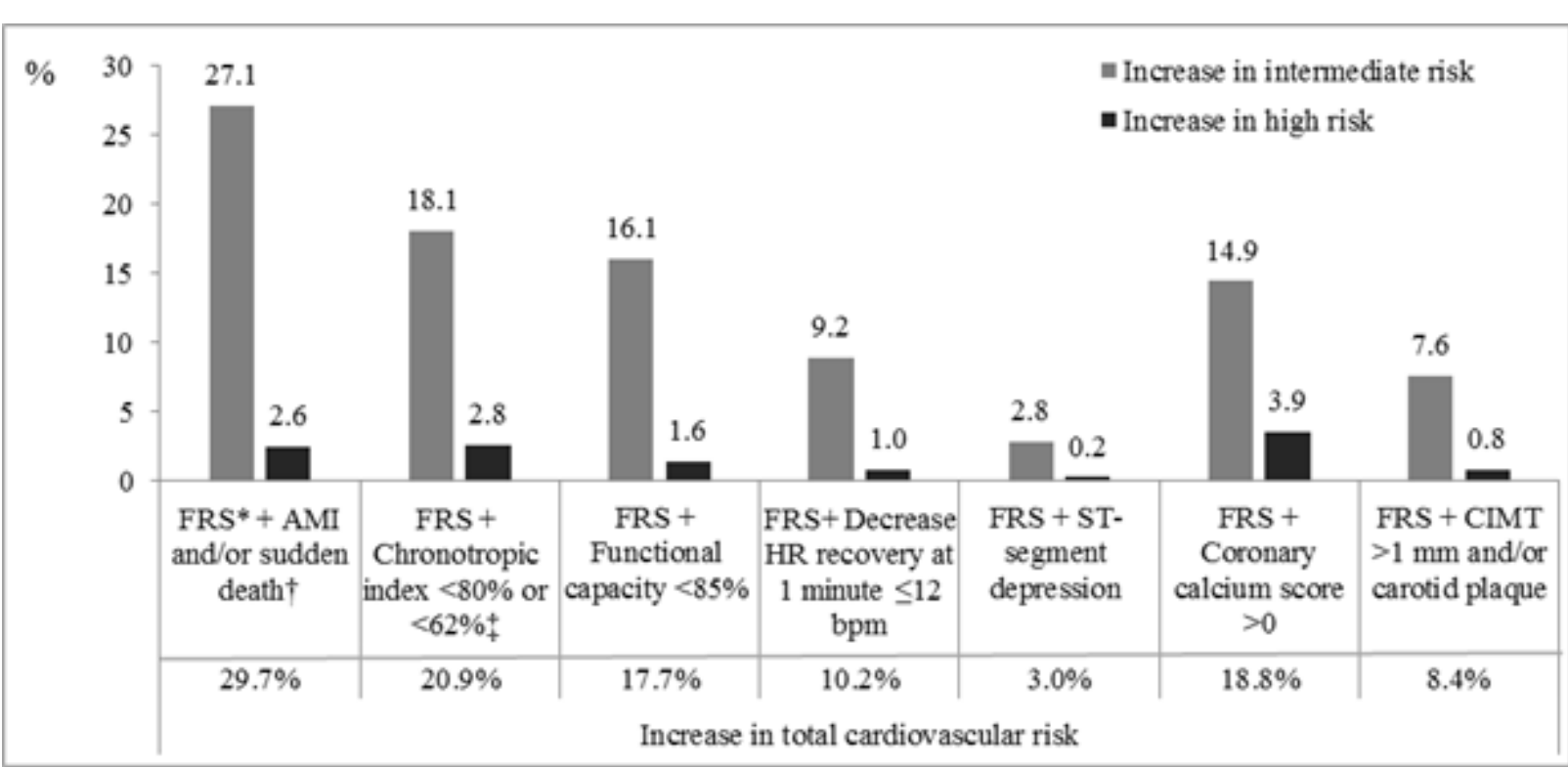

Figure 2 - Increase in cardiovascular risk by the addition of premature family history of cardiovascular events, exercise testing variables, and subclinical atherosclerosis markers to the Framingham Risk Score in asymptomatic middle-aged women FRS: Framingham Risk Score; AMI: acute myocardial infarction; HR: heart rate; CIMT: carotid intima-media thickness

${ }^{*} F R S$ : Framingham Risk Score; tHistory of acute myocardial infarction (AMI) and/or sudden death in parents and/or siblings younger than 55 years (men) or 60 years (women); $\neq$ Chronotropic index $<62 \%$ if using heart rate-lowering medication 
a positive family history, the addition of other variables to the risk score may identify and benefit those most vulnerable to cardiovascular events. ${ }^{39}$

Several variables have been proposed for reclassification of cardiovascular risk estimated by the FRS, $3,27,29$ varying from simple clinical history to more complex methods that are expensive or require advanced technology, such as cardiac imaging tests. The variables analyzed in the present study were previously shown to be associated with severe outcomes, ${ }^{3,11,16-18,23,26,29}$ including death, acute myocardial infarction, and stroke. Five of the seven variables showed a homogeneous distribution between the FRS strata, which reinforces the possible benefit of their addition to this traditional risk score.

A premature family history of cardiovascular events in parents and siblings has been independently associated with a higher incidence of cardiovascular events, even in women classified as low risk by the FRS. ${ }^{1,13,40,41}$ This is a class I variable in asymptomatic individuals ${ }^{10}$ obtained during the initial evaluation, regardless of other exams and at no additional cost.

The predictive factors of mortality, although easily assessed in exercise testing, are not always considered important in the interpretation of the test results, including in asymptomatic women, ${ }^{26,29,42}$ and are not considered for primary prevention. As noted in this study, about one-fifth of asymptomatic middle-aged women would be more closely monitored for their cardiovascular risk if abnormalities in the chronotropic index or functional capacity were added to the FRS. A low functional capacity is potentially reversible by physical activity programs aimed to reduce cardiovascular risk..$^{26,33,34,43,44}$ On the other hand, a good functional capacity is indicative of better prognosis, even in the presence of ischemia, elevated calcium score, or anatomical coronary disease. ${ }^{34,45,46}$ Also, the finding of a good functional capacity, can avoid the overvaluation of eventual ST-segment depression and the subsequent performance of unnecessary or even harmful exams.

In relation to the coronary calcium score and CIMT, studies $^{3,11,12}$ have shown that they add independent prognostic information to the FRS. In the present study, the increment in cardiovascular risk by the addition of CIMT $>1 \mathrm{~mm}$ and/or carotid plaque to the FRS was lower than that observed with the addition of a carotid calcium score $>0$. However, access to both tests may be costly and not possible in clinical practice. In this case, we consider the CIMT due to the higher feasibility and lack of radiation exposure.
Among the strengths of the study, our study population consisted of middle-aged women whose complaints may go unmonitored and uninvestigated, despite the increase in the prevalence and severity of cardiovascular diseases in this group. ${ }^{3,4,40}$ Middle-aged women have relatively low participation rates in clinical trials and scientific guidelines. ${ }^{47,48}$ In addition, we analyzed variables that are easily measured by exercise testing but not always valued in clinical practice..$^{21-23,49}$ It should be emphasized that exercise testing is a widespread, low-cost method, that does not involve radiation, with proven accuracy in different populations, including asymptomatic women. ${ }^{20,24,30}$ In this study, exercise testing was symptomlimited, rather than by maximal HR, which could have underestimated functional capacity. ${ }^{29,30}$

In the present study, we evaluated whether the addition of certain variables to the FRS would improve risk classification in asymptomatic middle-aged women, and propose that premature family history of cardiovascular events should be the first factor to be evaluated by clinicians in women classified at low or intermediate risk based on the FRS. Then, after risk reclassification, these women would undergo exercise testing and carotid artery ultrasound for assessment of markers of subclinical atherosclerosis, including the CIMT, and calcium score testing. In each stage, stricter recommendations for periodic follow-up and primary prevention strategies are recommended to early identify those women at higher risk of cardiovascular events.

This study was limited by its cross-sectional design, and the absence of monitoring the effect of adding family history, exercise testing parameters and subclinical atherosclerosis markers on cardiovascular outcomes of these women over time. However, the selection of variables for risk reclassification was based on cohort studies that evaluated severe outcomes such as death, acute myocardial infarction, and stroke..$^{3,11,16-18,26,29}$ It is also worth noting that all variables used in the present study to reclassify cardiovascular risk in asymptomatic middleaged women are currently recommended in national and international guidelines as factors for consideration in risk assessments. ${ }^{4,9,10,20}$

\section{Conclusions}

In asymptomatic middle-aged women, the study revealed an increase of $3.0-29.7 \%$ in cardiovascular risk estimated by the FRS with the addition of premature family history of acute myocardial infarction and/or 
sudden death, mortality predictive factors assessed by exercise testing, and subclinical atherosclerosis markers. This enabled risk reclassification of women classified as low or intermediate risk based on the FRS, and the possibility for a more effective control and reduction of the risk for cardiovascular events in this group of asymptomatic women.

\section{Acknowledgements}

The authors are grateful to the staff of Pernambuco Cardiac Emergency Center (Pronto Socorro Cardiológico de Pernambuco) and the Oswaldo Cruz University Hospital Study Center, both linked to the University of Pernambuco (Recife - PE, Brazil), for their collaboration and support in the development of the study.

\section{Author contributions}

Conception and design of the research: Coutinho RQ, Montarroyos UR, Barros IML, Guimarães MJB, Costa LOBF, Ferreira MNL, Chalela WA, Pedrosa RP. Acquisition of data: Coutinho RQ, Barros IML, Leão APD, Medeiros AKL, Monteiro MF. Analysis and interpretation of the data: Coutinho RQ, Montarroyos UR, Guimarães MJB, Pedrosa RP. Statistical analysis: Montarroyos UR. Obtaining financing: Barros IML. Writing of the manuscript: Coutinho RQ, Montarroyos UR, Guimarães MJB, Pedrosa RP. Critical revision

\section{References}

1. Fernandes CE, Pinho-Neto JSL, Gebara OCE, Santos Filho RD, Pinto Neto AM, Pereira Filho AS, et al. I diretriz brasileira sobre prevenção de doenças cardiovasculares em mulheres climatéricas e a influência da terapia de reposição hormonal (TRH) da Sociedade Brasileira de Cardiologia (SBC) e da Associação Brasileira do Climatério (SOBRAC). Arq Bras Cardiol. 2008;91(1 supl 1):1-23.

2. Woodard GA, Brooks MM, Barinas-Mitchell E, Mackey RH, Matthews KA, Sutton-Tyrrell K. Lipids, menopause and early atherosclerosis in swan heart women: menopausal transition and lipids. Menopause. 2011;18(4):376-84.

3. Lakoski SG, Greenland P, Wong ND, Schreiner PJ, Herrington DM, Kronmal RA, et al. Coronary artery calcium scores and risk for cardiovascular events in women classified as "low risk" based on Framingham risk score: The multi-ethnic study of atherosclerosis (MESA). Arch Intern Med. 2007;167(22):2437-42.

4. Goff DC Jr, Lloyd-Jones DM, Bennett G, Coady S, D'Agostino RB, Gibbons $\mathrm{R}$, et al. 2013 ACC/AHA guideline on the assessment of cardiovascular risk: a report of the American College of Cardiology/American Heart Association Task Force on Practice Guidelines. J Am Coll Cardiol. 2014; 63(25):2935-59.

5. Mosca L, Benjamin EJ, Berra K, Bezanson JL, Dolor RJ, Lloyd-Jones DM, et al. Effectiveness-based guidelines for the prevention of cardiovascular of the manuscript for intellectual content: Coutinho RQ, Montarroyos UR, Guimarães MJB, Ferreira MNL, Chalela WA, Pedrosa RP.

\section{Potential Conflict of Interest}

No potential conflict of interest relevant to this article was reported.

\section{Sources of Funding}

The study was partially funded by the Fundação de Amparo à Ciência e Tecnologia do Estado de Pernambuco (Brazil) - Facepe (process number: APQ-1386-4.00/08).

\section{Study Association}

This article is part of the doctoral thesis submitted by Ricardo Quental Coutinho to the University of Pernambuco.

\section{Ethics approval and consent to participate}

This study was approved by the Brazilian National Ethics Committee Registry, CAAE n. 0159.0.106.106-11. The research was conducted according to the principles of the Declaration of Helsinki (2013). Written informed consent was obtained from all participants included in the study, who were assured of adequate symptom control or changes in subclinical atherosclerosis markers, if required. disease in women-2011 update. A guideline from the American Heart Association. JACC. 2011;57(12):1404-23.

6. Précoma DB, Oliveira GMM, Simão AF, Dutra OP, Coelho OR, Izar COM, et al. Atualização da diretriz de prevenção cardiovascular da Sociedade Brasileira de Cardiologia - 2019. Arq Bras Cardiol. 2019;113(4):787-891.

7. Fernandes PV, Castro MM, Fuchs A, Machado MCR, Oliveira FD, Silva LB, et al. Valor preditivo do escore de Framingham da identificação de alto risco cardiovascular. Int J Cardiovasc Sci.2015;28(1):4-8.

8. Santos RD, Nasir K. Insights into atherosclerosis from invasive and noninvasive imaging studies: should we treat subclinical atherosclerosis? Atherosclerosis. 2009;205(2):349-56.

9. Faludi AA, Izar MCO, Saraiva JFK, Chacra APM, Bianco HT, Afiune Neto A, et al. Atualização da Diretriz Brasileira de Dislipidemias e Prevenção da Aterosclerose - 2017. Arq Bras Cardiol. 2017;109(2Supl.1):1-76.

10. Greenland P, Alpert JS, Beller GA, Benjamin EJ, Budoff MJ, Fayad ZA, et al. 2010 ACCF/AHA guideline for assessment of cardiovascular risk in asymptomatic adults: a report of the American College of Cardiology Foundation/American Heart Association Task Force on Practice Guidelines. J Am Coll Cardiol. 2010;56(25):e50-103. 
11. Lorenz MW, Markus HS, Bots ML, Rosvall M, Sitzer M. Prediction of clinical cardiovascular events with carotid intima-media thickness: a systematic review and meta-analysis. Circulation. 2007;115(4):459-67.

12. Sara L, Szarf G, Tachibana A, Shiozaki AA, Villa AV, Oliveira AC, et al Sociedade Brasileira de Cardiologia. II diretriz de ressonância magnética e tomografia computadorizada cardiovascular da Sociedade Brasileira de Cardiologia e do Colégio Brasileiro de Radiologia. Arq Bras Cardiol. 2014; 103(6Supl.3):1-86.

13. Michos ED, Vasamreddy CR, Becker DM, Yanek LR, Moy TF, Fishman EK, et al. Women with a low Framingham risk score and a family history of premature coronary heart disease have a high prevalence of subclinical coronary atherosclerosis. Am Heart J. 2005;150(6):1276-81.

14. Azevedo CF, Rochitte CE, Lima JAC. Escore de cálcio e angiotomografia coronariana na estratificação do risco cardiovascular. Arq Bras Cardiol. 2012;98(6):559-68

15. Greenland $\mathrm{P}$, Bonow RO, Brundage BH, Budoff MJ, Eisenberg MJ, Grundy SM, et al. ACCF/AHA 2007 clinical expert consensus documen on coronary artery calcium scoring by computed tomography in global cardiovascular risk assessment and in evaluation of patients with chest pain. J Am Coll Cardiol. 2007;49(3):378-402.

16. Detrano R, Guerci AD, Carr JJ, Bild DE, Burke G, Folsom AR, et al. Coronary calcium as a predictor of coronary events in four racial or ethnic groups. N Engl J Med. 2008;358(13):1336-45.

17. Budoff MJ, Shaw LJ, Liu ST, Weinstein SR, Mosler TP, Tseng PH, et al. Long-term prognosis associated with coronary calcification: observations from a registry of 25,253 patients. J Am Coll Cardiol. 2007;49(18):1860-70.

18. van den Oord SC, Sijbrands EJ, ten Kate GL, van Klaveren D, van Domburg RT, van der Steen AFW, et al. Carotid intima-media thickness for cardiovascular risk assessment: systematic review and meta-analysis. Atherosclerosis. 2013;208(1):1-11.

19. Freire CMV, Alcantara ML, Santos SN, Amaral SI, Veloso O, Porto CLL, et al. Recomendação para a quantificação pelo ultrassom da doença aterosclerótica das artérias carótidas e vertebrais: grupo de trabalho do Departamento de Imagem Cardiovascular da Sociedade Brasileira de Cardiologia - DIC - SBC. Arq Bras Cardiol: Imagem cardiovasc. 2015;28(nº especial):e1-e64

20. Meneguelo RS, Araújo CGS, Stein R, Mastrocolla LE, Albuquerque PF, Serra SM, et al. III diretriz da Sociedade Brasileira de Cardiologia sobre teste ergométrico. Arq Bras Cardiol. 2010; 95(5 supl 1):1-26.

21. Kligfield $\mathrm{P}$, Lauer MS. Contemporary reviews in cardiovascular medicine exercise electrocardiogram testing beyond the ST segment. Circulation. 2006;114:2070-82.

22. Fletcher GF, Ades PA, Kligfield P, Arena R, Balady GJ, Bittner VA et al on behalf of the American Heart Association Exercise, Cardiac Rehabilitation, and Prevention Committee of the Council on Clinical Cardiology, Council on Nutrition, Physical Activity and Metabolism, Council on Cardiovascular and Stroke Nursing, and Council on Epidemiology and Prevention). Exercise standards for testing and training: a scientific statement from the American Heart Association. Circulation. 2013;128:873-934.

23. Kohli P, Gulati M. Exercise stress testing in women: going back to the basics. Circulation. 2010;122(24):2570-80

24. Mieres JH, Gulati M, Bairey Merz N, Berman DS, Gerber TC, Hayes $\mathrm{SN}$, et al (on behalf of the American Heart Association Cardiac Imaging Committee of the Council on Clinical Cardiology; Cardiovascular Imaging and Intervention Committee of the Council on Cardiovascular Radiology and Intervention). Role of noninvasive testing in the clinical evaluation of women with suspected ischemic heart disease: a consensus statement from the American Heart Association. Circulation. 2014;130(4):350-79.

25. Frolkis JP, Pothier CE, Blackstone EH, Lauer MS. Frequent ventricular ectopy after exercise as a predictor of death. N Engl J Med. 2003;348(9):781-90.

26. Gulati M, Pandey DK, Arnsdorf MF, Lauderdale DS, Thisted RA Wicklund RH, et al. Exercise capacity and the risk of death in women: the St James Women Take Heart Project. Circulation. 2003;108(13):1554-9.
27. Gupta S, Rohatgi A, Ayers CR, Willis BL, Haskell WL, Khera A, et al. Exercise physiology cardiorespiratory fitness and classification of risk of cardiovascular disease mortality. Circulation. 2011;123:1377-83.

28. Kodama S, Saito K, Tanaka S, Maki M, Yachi Y, Asumi M, et al. Cardiorespiratory fitness as a quantitative predictor of all-cause mortality and cardiovascular events in healthy men and women a meta-analysis. JAMA. 2009;301(19):2024-35.

29. Mora S, Redberg RF, Cui Y, Whiteman MK, Flaws JA, Sharrett AR, Blumenthal RS. Ability of exercise testing to predict cardiovascular and all-cause death in asymptomatic women: a 20-year follow-up of the lipid research clinics prevalence study. JAMA. 2003;290(12):1600-7.

30. Balady GJ, Larson MG, Vasan RS, Leip EP, O’Donnell CJ, Levy D. Usefulness of exercise testing in the prediction of coronary disease risk among asymptomatic persons as a function of the Framingham risk score. Circulation. 2004;110(14):1920-5.

31. Cournot M, Taraszkiewick D, Cambou JP, Galinier M, Boccalon H, Hanaire-Broutin $\mathrm{H}$, et al. Additional prognostic value of physical examination, exercise testing, and arterial ultrasonography for coronary risk assessement in primary prevention. Am Heart J. 2009;158(5):845-51.

32. Chang SM, Nabi F, Xu J, Pratt CM, Mahmarian AC, Frias ME, et al. Value of CACS compared with ett and myocardial perfusion imaging for predicting long-term cardiac outcome in asymptomatic and symptomatic patients at low risk for coronary disease clinical implications in a multimodality imaging world. J Am Coll Cardiol Img. 2015;8(2):134-44.

33. DeFina L, Radford N, Leonard D, Gibbons L, Khera A. Cardiorespiratory fitness and coronary artery calcification in women. Atherosclerosis. 2014;233(2):648-53.

34. Choi SY, Sung J, Park HE, Han D, Chang HJ. Combined effects of exercise capacity and coronary atherosclerotic burden on all-cause mortality in asymptomatic Koreans. Atherosclerosis. 2016;251:396-403.

35. Scheaffer RL, Mendenhall W, Ott RL, Gerow KG. Elementary Survey Sampling. 7th edn. Massachusetts, USA: Cengage Learning, 2011:480p.

36. Bruce RA, Kusumi F, Hosmer D. Maximal oxygen intake and nomographic assessment of functional aerobic impairment in cardiovascular disease. American Heart Journal. 1973;85(4):546-51.

37. Karvonen MJ, Kentala E, Mustala O. The effects of training on heart rate; a longitudinal study. Ann Med Exp Biol Fenn. 1957;35(3):307-15.

38. Agatston AS, Janowitz WR, Hildner FJ, Zusmer NR, Viamonte M Jr, Detrano R. Quantification of coronary artery calcium using ultrafast computed tomography. J Am Coll Cardiol. 1990;15(4):827-32.

39. Gomes BFO, Oliveira GMM. What is the best cardiovascular risk score for the Brazilian population? Int J Cardiovasc Sci. 2020;33(6):627-28.

40. Benjamin EJ, Blaha MJ, Chiuve SE, Cushman M, Das SR, Deo R, et al. Heart Disease and Stroke Statistics- 2017 Update: A Report From the American Heart Association. Circulation. 2017;135(10):e146-e603.

41. Suh B, Shin DW, Lee SP, Lee H, Lee H, Park E-A, et al. Family history of coronary heart disease is more strongly associated with coronary than with carotid atherosclerosis in healthy asymptomatic adults. Atherosclerosis. 2014;233(2):584-9.

42. Coutinho RQ, Montarroyos UR, Barros IML, Guimarães MJB, Costa LOBF, Medeiros AKL, et al. Non Electrocardiographic alterations in exercise testing in asymptomatic women. Associations with cardiovascular risk factors. Clinics. 2019;74:e1005.

43. Arnson Y, Rozanski A, Gransar H, Hayes SW, Friedman JD, Thomson LEJ, et al. Impact of Exercise on the relationship between CAC scores and all-cause mortality. JACC Cardiovasc Imaging. 2017;10(12):146-68.

44. Blaha MJ, Feldman DI, Nasir K. Coronary artery calcium and physical fitness - the two best predictors of long-term survival. Atherosclerosis. 2014;234(1):93-4.

45. Bourque JM, Holland BH, Watson DD, Beller GA. Achieving an exercise workload of $>$ or $=10$ metabolic equivalents predicts a very low risk of inducible ischemia: does myocardial perfusion imaging have a role? J Am Coll Cardiol. 2009;54(6):538-45. 
46. Vivekananthan DP, Blackstone EH, Pothier CE, Lauer MS. Heart rate recovery after exercise is a predictor of mortality, independent of the angiographic severity of coronary disease. J Am Coll Cardiol. 2003;42(5):831-8.

47. Kim ES, Menon V. Status of women in cardiovascular clinical trials. Arterioscler Thromb Vasc Biol. 2009;29(3):279-83.
48. Melloni C, Berger JS, Wang TY, Gunes F, Stebbins A, Pieper KS, et al. Representation of Women in Randomized Clinical Trials of Cardiovascular Disease Prevention. Circ Cardiovasc Qual Outcomes. 2010;3(2):135-42.

49. Santos MON, Mees AV, Moraes Júnior A, Santos LR, Leão MO, Rafael $\mathrm{PF}$, et al. Avaliação crítica sobre acurácia do teste ergométrico na prática clínica: experiência de centro único. Rev Bras Cardiol. 2012;25(3):177-184. 